\title{
Surgical management of fractures of distal end radius with locking compression plate
}

\author{
Lakshman Prasath $\mathbf{G}^{1}$, Arun $\mathrm{R}^{2}$, Shankar Radhakrishnan ${ }^{3}$ \\ ${ }^{1}$ Dr. Lakshman Prasath Govindarajan, Assistant Professor, Department of Orthopaedics, Annapoorna Medical College \\ and Hospital, Salem, ${ }^{2}$ Dr. Arun Rajamanickam, Senior Resident, Department of Orthopaedics, Vinayaka Missions \\ Kirupananda Variyar Medical College and Hospital, Salem, ${ }^{3}$ Dr. Shankar Radhakrishnan, Vinayaka Missions \\ Kirupananda Variyar Medical College and Hospital, Salem, Tamil Nadu India.
}

Corresponding Author: Dr Arun Rajamanickam, Senior Resident, Department of Orthopaedics, Vinayaka Missions Kirupananda Variyar Medical College and Hospital, Salem, Email-shnkr_radhakrishnan@yahoo.com

\begin{abstract}
Background: Use of fixed angle locking plates with locking screws for fractures of distal radius support the subchondral bone and resist axial forces and an additional benefit is it provides additional strength to fixation by constructing a scaffold under the distal radial articular surface. Aim: To assess the functional outcome of fracture of distal end of radius managed with locking compression plates. Methodology: A prospective longitudinal study was conducted at our hospital for a period of two years. Totally thirty-two patients were included in the study. The fracture fragments were analysed and involvement of radiocarpal and distal radioulnar joints were assessed and classified according to the Frykman's and AO classification. The appropriate plate is selected following the fracture reduction. Once stable fixation was achieved and hemostasis secured, the wound was closed in layers and sterile compression dressing was applied. All the patients were followed up for a period of 6 months. Results: The outcome evaluation was measured based on demerit score system of Gartland and Werley and for $97 \%$ of the patients the results was in the range of good and excellent and for only one patient it was fair and none of the patient had a poor result. Conclusion: Volar approach provides both access with minimal surgical trauma on distal radius and fixation with a better adaptation to surrounding tissues.
\end{abstract}

Keywords: Radius fracture, compression plate, Gartland and Werley scoring system.

\section{Introduction}

Fractures of the distal end of radius are the most common fractures in the upper extremity and it constitutes to $75 \%$ of all forearm fractures. High velocity injuries have resulted in severely comminuted and unstable fractures with intra articular components.

Fractures of distal end of radius continue to pose a therapeutic challenge. Intra-articular and extra-articular malalignment can lead to various complications like post traumatic osteoarthrosis, decreased grip strength and endurance, as well as limited motion and carpal instability [1]. Many methods like closed reduction and casting, pins and plaster, percutaneous pinning, external fixation with ligamentotaxis, internal fixation, combined internal and external fixationand arthroscopically assisted reduction have come up for treating the fractures in the distal end of radius [2].

\footnotetext{
Manuscript Received: $7^{\text {th }}$ January 2018

Reviewed: $17^{\text {th }}$ January 2018

Author Corrected: $25^{\text {th }}$ January 2018

Accepted for Publication:31 ${ }^{\text {st } J a n u a r y ~} 2018$
}

Surgical Update: International Journal of Surgery \& Orthopedics
In a young patient with a severely comminuted fracture, acceptable closed reduction may be achieved easily but it would be difficult to maintain. When the reduction is lost certain complications such as a shortened, dorsally angulated carpus with subsequent poor function and early changes of osteoarthiritis secondary to articular incongruity may occur resulting in poor functional and cosmetic outcome $[3,4]$. Though closed reduction and cast immobilization has been the mainstay of treatment for these fractures because of the above-mentioned complications it is now replaced by open reduction and plating.

Internal fixation of metaphyseal bending fractures has become increasingly popular due to its direct control and maintenance of physiologic palmar kit, prevent collapse with external fixation and avoid bridging the radiocarpal joint [5]. The distal fragment typically has sufficient size and integrity to provide adequate purchase and may be approached from either a dorsal or 


\section{Original Research Article}

a volar approach. Palmar plating is usually preferred as the screws directly buttress against collapse and may lead to loss of palmar tilt. With smaller and more distal fragments, a dorsal plate has to be positioned distally on the dorsum of the radius making extensor tendon injury more likely [6].

There are two types of plates for fractures of distal radius one is conventional plates and the other is fixed angle locking compression plates. Using conventional plates has some disadvantages like comminution must be less and they poorly hold the cancellous bone fragments and due to the toggle of screws in the distal holes of the plate it leads to settling and loss of reduction of the fracture.

With conventional plates and screws, stability is achieved by compression of plate by using bicortical screws $[7,8]$. With fixed angle locking plates the locking screws support the subchondral bone and resist axial forces and the additional benefit of using the fixed angle construct is it provides additional strength to fixation by constructing a scaffold under the distal radial articular surface [9].

In the modern era volar fixed angle locking plates found to be an effective treatment for unstable extra articular distal radius fractures as it allows early post-operative rehabilitation and because of its angular stability of locking compression plates, reduction can be maintained over times so that secondary displacement is no longer a problem.

Primary stability achieved with locking screw in a plate prevents secondary displacement irrespective of the condition of the bone either in osteoporotic bones or in young patients it enables excellent results [10]. As of today, only very few studies had been conducted in evaluating the functional outcome of distal end radius fracture managed using volar locking compression plates and so this study was undertaken in evaluating the compression plates used for treating distal radius fractures.

Aim: To assess the functional outcome of fracture of distal end of radius managed with locking compression plates.

\section{Methodology}

Study design: Prospective longitudinal study.

Study area: Department of Orthopaedics, Annapoorna Medical College and Hospital, Salem.
Study period: From July 2013 to August 2015.

Sampling: Non-random sampling was followed in which all the patients in the above-mentioned period fitting into our inclusion and exclusion criteria were selected as our study subjects

Inclusion criteria: patients more than 18 years of age presenting with simple fractures and compound fractures without vascular injury.

Exclusion criteria: Patients with less than 18 years of age and compound fractures associated with vascular injury were excluded from the study.

Surgical procedure: All the patients presented with elbow flexed and the wrist supported by the other hand. Careful inspection of the deformity, swelling and ecchymosis were done. Clinically tenderness, bony irregularity, crepitus and relative position of radial and ulnar styloid process were elicited. Movements of the wrist and forearm were checked and found to be painful and limited.

Distal vascularity was assessed by radial artery pulsations, capillary filling, pallor and paraesthesia over finger tips. The involved forearm was immobilised with a below elbow POP and kept elevated. Pain and inflammation were managed using analgesics.

X-rays of PA and lateral view were taken for confirmation of the diagnosis and to assess the type of fracture. The fracture fragments were analysed and involvement of radiocarpal and distal radioulnar joints were assessed and classified according to the Frykman's and AO classification. The duration from the date of injury to the date of operation ranged from $1-6$ days. All the routine blood investigations were done and the fitness from physician and anaesthetist were obtained.

The patient was placed supine on the operating table. The affected limb was elevated for $2-3$ minutes and exsanguinated. Then a mid-arm pneumatic tourniquet was applied and the limb was placed on a side arm board. The incision for volar fixation of the distal radius is typically performed through the distal extent of the Henry's approach. An incision is made between the flexor carpi radialis tendon and the radial artery.

After exposure and debridement of the fracture site, the fracture is reduced and provisionally fixed under fluoroscopy with K-wires, reduction forceps or suture fixation. The appropriate plate is selected following the 
fracture reduction. First a standard cortical screw was applied to the most distal oval hole of the vertical limb of the plate in order to temporarily secure the plate to the proximal fragment. This allowed concomitant proximal and distal plate adjustment. After fixing the distal fragment with subchondral locking screws, radial length was gained when necessary by passing the plate distally.

The first standard screw can be either left insitu or exchanged with another locking screw; the oval hole is a combination hole designed for locking head screw placement at the distal end and standard screw placement at the proximal end of the same hole.

The optimal placements of the distal screws were important; they were inserted at the radial styloid, beneath the lunate facet and near the sigmoid notch. The distal screws can be of either monocortical or bicortical engagement. More volar tilt was achieved during distal screw placement when the wrist is volarly flexed as much as possible by an assistant. Moreover, radial length was further improved by pushing the whole plating system distally while using the oval plate hole and screw as a glide. The final position of the palte was confirmed using fluoroscopy.

Once stable fixation was achieved and hemostasis secured, the wound was closed in layers and sterile compression dressing was applied. The tourniquet was removed and capillary refilling was checked in the fingers.

The operated limb was supported with an anterior below elbow POP slab with the wrist in neutral position. All the patients were followed up for a period of 6 months.

Statistical analysis: All data were entered and analysed using SPSS version 21. Mean and standard deviation were calculated for all the parametric variables and percentage was derived for all the frequency variables involved in the study.

\section{Results}

The age and gender wise distribution of the study subjects shows that majority of the patients were in the age group between 30 and 50 years and the mean age was 39.6 years and the males outnumbered females with a male: female ratio of 3.5: 1 (table 1). Among all these fractures 30 were closed fractures and only two were open fractures and $70 \%$ were intra-articular fractures and $30 \%$ were extra-articular fractures.

Table-1: Age and sex wise distribution of the study population.

\begin{tabular}{|c|c|c|c|}
\hline \multirow{2}{*}{ Age group } & \multicolumn{2}{|c}{ Gender } & \multirow{2}{*}{ Total } \\
\cline { 2 - 4 } & Male & Female & $5(15.6 \%)$ \\
\hline $20-30$ & $4(16 \%)$ & $1(14.2 \%)$ & $9(28.2 \%)$ \\
\hline $31-40$ & $6(24 \%)$ & $1(14.2 \%)$ & $10(31.2 \%)$ \\
\hline $41-50$ & $9(36 \%)$ & $2(28.5 \%)$ & $6(18.7 \%)$ \\
\hline $51-60$ & $4(16 \%)$ & 0 & $2(6.2 \%)$ \\
\hline $61-70$ & $2(8 \%)$ & $\mathbf{7 ( 1 0 0 \% )}$ & $\mathbf{3 2}(\mathbf{1 0 0} \%)$ \\
\hline
\end{tabular}

Table-2: Distribution of the study subjects based on the mode of injury

\begin{tabular}{|c|c|c|}
\hline Mode of injury & Frequency & Percentage \\
\hline Road traffic accident & 18 & $56.2 \%$ \\
\hline Fall on out-stretched hand & 14 & $43.7 \%$ \\
\hline Total & $\mathbf{3 2}$ & $\mathbf{1 0 0} \%$ \\
\hline
\end{tabular}

More than $50 \%$ of the study subjects acquired the fracture of lower end radius through road traffic accident and only $43 \%$ had a fall on out-stretched hand. 
Original Research Article

Table-3: Distribution of the study subjects based on the type of fracture according to Frykman's Classification

\begin{tabular}{|c|c|c|}
\hline Type of fracture & Frequency & Percentage \\
\hline I & 6 & $18.7 \%$ \\
\hline II & 4 & $12.5 \%$ \\
\hline III & 9 & $28.1 \%$ \\
\hline IV & 5 & $15.6 \%$ \\
\hline V & 2 & $6.2 \%$ \\
\hline VI & 1 & $3.1 \%$ \\
\hline VII & 0 & 0 \\
\hline VIII & 5 & $15.6 \%$ \\
\hline Total & $\mathbf{3 2}$ & $\mathbf{1 0 0} \%$ \\
\hline
\end{tabular}

The distal end radius fractures were classified based on Frykman's classification which has types and among them type III found to be more common in our patients which is intra-articular fractures involving the radio carpal joint followed by type I which is a transverse metaphyseal fracture (table 3).

Table-4: Distribution of the study subjects based on the type of fracture according to AO classification

\begin{tabular}{|c|c|c|}
\hline AO type & Frequency & Percentage \\
\hline A1 & 0 & 0 \\
\hline A2 & 4 & $12.5 \%$ \\
\hline A3 & 6 & $18.7 \%$ \\
\hline B1 & 3 & $9.3 \%$ \\
\hline B2 & 5 & $15.6 \%$ \\
\hline B3 & 5 & $15.6 \%$ \\
\hline C1 & 6 & $18.7 \%$ \\
\hline C2 & 3 & $9.3 \%$ \\
\hline C3 & 0 & 0 \\
\hline Total & 32 & $100 \%$ \\
\hline
\end{tabular}

Fracture were also further classified based on AO classification and among them A3 (Extra-articular radius, multi fragmentary), B3 (partial articular radius, frontal, volar rim) and C1 (complete articular simple metaphyseal) were found to be the more common types (table 4).

Table-5: Distribution of the study subjects based on the associated injuries

\begin{tabular}{|c|c|c|}
\hline Associated injuries & Frequency & Percentage \\
\hline Ipsilateral fracture shaft of femur & 1 & $20 \%$ \\
\hline Contusional head injury & 1 & $20 \%$ \\
\hline Ipsilateral lower third ulnar fracture & 1 & $20 \%$ \\
\hline Right superior pubic rami fracture & 2 & $40 \%$ \\
\hline Total & 5 & $100 \%$ \\
\hline
\end{tabular}

Table- 6: Distribution of the study subjects based on the duration of fracture union.

\begin{tabular}{|c|c|c|}
\hline Duration of fracture union & Frequency & Percentage \\
\hline $2-3$ months & 27 & $84.3 \%$ \\
\hline $3-4$ months & 3 & $9.3 \%$ \\
\hline$>4$ months & 2 & $6.2 \%$ \\
\hline Total & $\mathbf{3 2}$ & $\mathbf{1 0 0} \%$ \\
\hline
\end{tabular}


Original Research Article

Table-7: Distribution of the study subjects based on the range of motion

\begin{tabular}{|c|c|c|}
\hline Range of movements (within normal functional range) & Frequency & Percentage \\
\hline Dorsiflexion $\left(\min 45^{0}\right)$ & 32 & $100 \%$ \\
\hline Palmar flexion $\left(30^{0}\right)$ & 32 & $100 \%$ \\
\hline Pronation $\left(50^{0}\right)$ & 32 & $100 \%$ \\
\hline Supination $\left(50^{0}\right)$ & 32 & $100 \%$ \\
\hline Radial deviation $\left(15^{0}\right)$ & 29 & $90.6 \%$ \\
\hline Ulnar deviation $\left(15^{0}\right)$ & 30 & $93.7 \%$ \\
\hline Pain in distal radioulnar joint & 2 & $6.25 \%$ \\
\hline Grip strength $(60 \%$ or less than on opposite side) & 1 & $3.1 \%$ \\
\hline
\end{tabular}

Table-8: Outcome evaluation of the study subjects based on the Demerit score system of Gartland and Werley

\begin{tabular}{|c|c|c|}
\hline Results & Frequency & Percentage \\
\hline Excellent & 16 & $50 \%$ \\
\hline Good & 15 & $46.8 \%$ \\
\hline Fair & 1 & $3.1 \%$ \\
\hline Poor & 0 & 0 \\
\hline Total & 32 & $100 \%$ \\
\hline
\end{tabular}

Among the various associated injuries out of 32 patients only 5 patients had some associated injuries like ipsilateral lower third ulnar fracture, superior pubic rami fracture and other injuries were illustrated in table 5. All the patients were investigated and anaesthetist opinion was obtained and was operated. The mean duration between the time of fracture and surgery was 3.3 days. After the surgery the patients were followed for a period of 6 months and none of the patients had immediate post-operative complications and for $85 \%$ of the subjects the fracture reunion had occurred in $2-3$ months and for only two patients it took more than 4 months for the union (table 6). According to the range of motion which was assessed 16 weeks post-operatively we found dorsiflexion, palmar flexion, pronation and supination was almost in the normal range for all the patients and only 2 patients had pain in the radio-ulnar joint and for one patient the grip strength was $60 \%$ and less (table 7). Only 2 patients had complications in our entire study subjects, one patient had developed arthritis and the other patient had extensor policies longus tendon irritation. The outcome evaluation was measured based on demerit score system of Gartland and Werley and for $97 \%$ of the patients the results was in the range of good and excellent and for only one patient it was fair and none of the patient had a poor result (table 8).

\section{Discussions}

Distal radius fractures are the most frequently seen upper extremity fractures among people with all age group. The main objective of its treatment is the reestablishment of anatomic integrity and functioning. In unstable intra-articular fractures, re-establishment of interarticular integrity of the wrist and maintaining the radial length are often not possible with closed methods.

A better understanding of wrist anatomy and functioning through the studies conducted in the recent years, as well as the increasing expectations of patients have expanded the borders of surgical treatment and improvements in fixation materials have provided new opportunities. Over the last one decade most of the studies were conducted towards clarifying the best surgical treatment for fracture of the distal extremity of the radius. In this context a recent study by Osada et al had documented the increasing popularity of open reduction and internal fixation, especially since the introduction of locked volar plates in 2001 [11]. The study had demonstrated that locked volar plates were well tolerated and it had allowed early mobilization and it had provided good support for deforming muscle forces after the surgical reduction, even among patients with intra-articular fractures. The majority of the studies have used subjective tools for measuring quality of life, such as the Gartland and Werley calculation and the DASH calculation while others have given greater emphasis to the radiographic parameters obtained after surgical reduction of fractures of the distal extremity of the radius [12-14].

In the present study patients were evaluated by the time taken for fracture union, range of motion and through 
the demerit score system of Gartland and Werley. The study subjects were in the age group of 20 to 70 years with a mean age of 39.6 years. A study done by Kevin $\mathrm{C}$, Chung et al the average age of the patients was 48.9 years with minimum age of 18 years and a maximum of 83 years.11 and another study by Rohit A et al the average age of the patients was 57 years with minimum age 17 years and maximum years 79 [15,16]. A similar study done by Killic A et al average age of the patients was 45 [17]. So the mean age of the present study was found to be lesser than the previous studies. In the present study we found majority were males with a male: female ratio of 3.5: 1, whereas the study done by Hanae Minegishi et al had shown females were $80 \%$ and another study by Tank Gyaneshwar females found to be $65 \%[18,19]$. A study by Margaret Fok WM et al study there were $56(57.7 \%)$ male and 41 (42.3\%) [20].

In our study more than $50 \%$ of the subjects had RTA and $43 \%$ had a history of fall with outstretched hand and similar studies in the past had also shown similar results. The present study shows only 5 patients had some associated injuries like ipsilateral lower third ulnar fracture, superior pubic rami fracture whereas the study done by Jacob etal and Agarwal K etal had shown the percentage of associated injuries as $28.8 \%$ and $62.5 \%$ respectively $[21,22]$.

Proposed advantages of locked volar plating include improved pull out strength even in osteoporotic bone [23]. Internal fixation using a dorsal plate, which is greatly advocated, achieves anatomical reduction with good stability. However, a variety of complication has been documented, including irritation of subcutaneous tissue, tenosynovitis of extensor muscle, rupture of extensor tendon and even chronic pain [24].

The outcome of the present study based on Gartland and Werley scoring system had shown that $97 \%$ of the subjects had an excellent to good results and only $3 \%$ had a fair outcome and none of them had a poor outcome, several studies have been done to assess the functional outcome of volar locking plate for intra articular distal radius fractures using Gartland and Werley scoring system. The initial study done by $\mathrm{H}$. Drobetz et al using Volar locking plates had reported excellent results in $26(52 \%)$, good in $20(40 \%)$, fair in $3(6 \%)$ and poor in $1(2 \%)$ patients according to Gartland and Werley scoring system [25]. Another study done Andrew W Beharrie et al reported $83 \%$ excellent and $17 \%$ good in elderly patients according to Gartland and Werley using LCP [26]. A study done in China by KK Wong etal had reported 24 (80\%) excellent, 5 (16.7\%) good, 1 (3.3\%) fair according to Gartland and Werley using LCP [27]. A recent Indian study by Pattanashetty et al reported $6(18.7 \%)$ patient had excellent results, 15 (46.8\%) patients had good results, $6(18.7 \%)$ patients had fair results and $5(15.6 \%)$ patients had poor results [28]. Most of the results of the previous studies were almost in par with the results of our study. One of the major limitations of the present study is the sample size as only 32 patients were included in this study, so more studies of this nature with larger sample size would help to further evaluate the efficacy of volar locking plates.

\section{Conclusion}

The study shows that using locking compression plates for fractures of distal end radius is excellent to good for $97 \%$ of patients and it is proved to be an effective method to maintain the reduction till union and prevent collapse of the fracture fragments, even when the fracture is grossly comminuted/intra-articular/unstable and/or the bone is osteoporosed. The procedure is applicable for AO types A, B and C fractures of the distal radius, in young patients with a good bone stock as well as in elderly osteoporotic patients. Volar approach provides both access with minimal surgical trauma on distal radius and fixation with a better adaptation to surrounding tissues.

\section{Contribution of different authors during study process and manuscript preparation}

1. Dr. Lakshman Prasath Govindarajan- Doing the surgeries for the patients and documenting the data. Collecting the references for the study.

2. Dr.Arun Rajamanickam - Assisting for the surgeries, examining the patients during the regular follow-up. Writing the discussion part for the study.

3. Dr. Shankar Radhakrishnan - assisting in writing the results and entering the data in the appropriate statistical software.

What Study adds to the existing knowledge- There are various modalities of treatment for distal radius fracture which includes plaster cast application, Kirschner wire fixation, dorsal and volar plates, and external fixation, have been described for the management of these fractures. Since these treatment options had more incidence of complications and failure rates usage of locking volar plates which mechanically bridge the bone and bear the load through the locking construct, resulting in a lower incidence of failure.

Conflict of interest: None declared. Funding: Nil, Permission from IRB: Yes 


\section{References}

1. Chen Neal C, Jupiter Jesse BMO. Management of distal radial fractures. The J Bone \& Joint Surg. 2007; 89- A(9):2051-2062.

2. Cooney WPIII, Dobyns JH, Linscheid RL. Complications of colles'fractures. J Bone Joint Surg. 1980; 62(4):613-619.

3. Bradway JK, Amadio PC, Cooney WP III. Open reduction and internal fixation of displaced, Comminuted intraarticular fractures of the distal end of the radius. J Bone Joint Surg. 1989; 71-A(6):839-847.

4. Musgrave DS, Idler RS. Volar fixation of dorsally displaced distal radius fractures using the $2.4 \mathrm{~mm}$ locking compression plates. J Hand Surg (Am). 2005; 30 (4): 743-9. DOI:10.1016/j.jhsa. 2005.03.006

5. Solgaard S, Petersen VS. Epidemiology of distal radius fractures. Acta Orthop Scand, 1985; 56 (5): 391-393.

6. Swiontkowski MF. Increasing rates of forearm fractures in children. JAMA 2003; 290 (24):3193. DOI: 10.1001/jama.290.24.3193-c

7. Lester GE, Anderson JJ, Tylavsky FA et al. Update on the use of distal radial bone density measurements in prediction of hip and Colles' fracture risk. J Orthop Res. 1990; 8 (2):220-226. DOI:10.1002/jor.1100080210

8. Chung KC, Watt AJ, Kotsis SV. Treatment of unstable distal radial fractures with the volar locking plating system. J Bone Joint Surg Am. 2006;88 (12): 2687-94. DOI:10.2106/JBJS.E.01298

9. Arora R, Lutz M, Hennerbichler A, Krappinger D. Complications following internal fixation of unstable distal radius fracture with a palmar locking-plate. J Orthop Trauma. 2007;21(5):316-22. DOI:10.1097/BOT. 0b013e318059b993

10. Kilic A, Kabukcuoglu Y, Ozkaya U, Gul M, Sokusu S, OzdoganU.Volar locking plate fixation of unstable distal radius fractures. Acta Orthop Traumatol Turc. 2009; 43(4):303-8. DOI:10.3944/AOTT.2010.2275

11. Osada D, Kamei S, Masuzaki K, Takai M, Kameda M, Tamai K. Prospective study of distal radius fractures treated with a volar locking plate system. J Hand Surg Am. 2008; 33 (5): 691-700. DOI:10.1016/j.jhsa. 2008. 01.024 .
12. Van Eerten PV, Lindeboom R, Oosterkamp AE, Goslings JC. An X-ray template assessment for distal radial fractures. Arch Orthop Trauma Surg. 2008;128 (2): 217-21. doi: 10.1007/s00402-007-0391-y

13. Gruber G, Zacherl M, Giessauf C, Glehr M, Fuerst F, Liebmann W. Quality of life after volar plate fixation of articular fractures of the distal part of the radius. $J$ Bone Joint Surg Am. 2010;92(5):1170-8. doi: 10.2106 /JBJS.I.00737.

14. Lozano-Calderón S, Moore M, Liebman M, Jupiter JB. Distal radius osteotomy. In The elderly patient using angular stable implants and norian bone cement. J Hand Surg Am. 2007; 32(7):976-83. DOI:10.1016/j.jhsa. 2007. 05.005

15. Chung KC, Watt AJ, Kotsis SV. Treatment of unstable distal radial fractures with the volar locking plating system. J Bone Joint Surg Am. 2006;88 (12): 2687-94. DOI:10.2106/JBJS.E.01298

16. Arora R, Lutz M, Hennerbichler A, Krappinger D. Complications following internal fixation of unstable distal radius fracture with a palmar locking-plate. J Orthop Trauma. 2007;21(5):316-22. DOI:10.1097/BOT. ob013e318059b993

17. Kilic A, Kabukcuoglu Y, Ozkaya U, Gul M, Sokusu S, OzdoganU.Volar locking plate fixation of unstable distal radius fractures. Acta Orthop Traumatol Turc. 2009; 43(4):303-8.

18. Minegishi H, Dohi O, An S, Sato H. Treatment of unstable distal radius fractures with volar locking plate. Ups J Med Sci. 2011; 116 (4):280-4. doi: 10.3109/ 03009734. 2011.594183

19. Tank G, Gupta AK, Parvez A, Singh G, Jaiswal S, Kumar A. Anatomical and functional evaluation of distal end radius fractures managed by volar plating. Pros study J evol Med dental Sci. 2013;7(2):802.

20. Fok MWM, Klausmeyer MA, Fernandez DL, Orbay JL, Bergada AL. Volar plate fixation of intra-articular distal radius fractures : A retrospective Study J Wrist Surg. 2013;2(3):247-54. doi: 10.1055/s-0033-1350086

21. Jakob M, Rikli DA, Regazzoni P. Fractures of distal radius treated by internal fixation and early fuction. $J$. Bone Joint Surg. 2000;82-B;340-4. 
22. Aggarwal AK, Nagi ON. Open reduction and internal fixation of volar Bartons fractures: A prospective study J ortho sur. 2004;12(2):230-4. DOI: $10.1177 / 230949900401200218$

23. Mudgal CS, Jupiter JB. Plate fixation of osteoporotic fractures of the distal radius. J. Orthop Trauma. 2008; 22 (8): S106-15. doi: 10. 1097/BOT. 0b013e 31815e9fcd.

24. Sobky K, Baldini T, Thomas K, Bach J, Williams A, Wolf JM. Biomechanical comparison of different volar fracture fixation plates for distal radius fractures. Hand (N Y). 2008; 3 (2):96-101. doi: 10.1007/s11552-0079074-y

25. Drobetz H, Kutscha-Lissberg E. Osteosynthesis of distal radial fractures with a volar locking screw plate system. Int Orthop. 2003; 27 (1):1-6. DOI: 10.1007/s 00264-002-0393-x.
26. Beharrie AW, Beredjiklian PK, Bozentka DJ. Functional outcomes after open reduction and internal fixation for treatment of displaced distal radius fractures in patients over 60 years of age. J Orthop Trauma. 2004 Nov-Dec;18(10):680-6.

27. Wong KK, Chan KW, Kwok TK, Mak KH. Volar fixation of dorsally displaced distal radial fracture using locking compression plate. Journal of Orthopaedic Surgery. 2005; 13 (2): 153-157. doi.org/10. 1177/23094 9900501300208

28. Pattanashetty OB, Shushrut B, Monish b. outcome of fracture distal end of radius in adults treated by open reduction and internal fixation with buttress plate. Kerala Journal of Orthopaedics Issue.2013;26(2): 87-92.

\section{How to cite this article?}

Lakshman Prasath G, Arun R, Shankar Radhakrishnan. Surgical management of fractures of distal end radius with locking compression plate. Surgical Update:Int J surg Orthopedics.2018;4(1):12-19. doi:10.17511/ijoso.2018.i01.03. 